\title{
Perfil metabólico de touros da raça Nelore (Bos taurus indicus) confinados e tratados com somatotrofina bovina recombinante (r-bST)
}

\author{
[Metabolic and hormonal profile of feedlot Nellore bulls (Bos taurus indicus) and treated with recombinant bovine \\ somatotropin $(r-b s t)]$
}

\author{
L.S. Amorim ${ }^{1}$, C. A. A. Torres ${ }^{2}$, E.A. Moraes ${ }^{1}$, J.M. Silva Filho ${ }^{3}$, J.D. Guimarães ${ }^{4}$ \\ ${ }^{1}$ Aluno de pós-graduação - UFV - Viçosa, MG. \\ ${ }^{2}$ Departamento de Zootecnia - UFV \\ Avenida P.H. Rolfs, $\mathrm{s} / \mathrm{n}$ \\ 36570-000 - Viçosa, MG \\ ${ }^{3}$ Escola de Veterinária - UFMG - Belo Horizonte, MG \\ ${ }^{4}$ Departamento de Veterinária - UFV - Viçosa, MG
}

\begin{abstract}
RESUMO
Avaliaram-se os efeitos da administração da somatotrofina bovina recombinante (r-bST) sobre os metabólitos sangüíneos de touros da raça Nelore de duas diferentes idades. Foram utilizados 16 touros, distribuídos em um delineamento fatorial $2 \times 2$ (idades: jovens e adultos; r-bST: 0 e $500 \mathrm{mg}$ ) com quatro animais por tratamento. A idade média dos animais foi de 13,37 e 20,62 meses para jovens e adultos, respectivamente. Quatro animais por tratamento receberam, a cada 14 dias, solução salina ou $500 \mathrm{mg}$ de r-bST, totalizando nove aplicações por animal, em um período experimental de 120 dias. Os touros foram alimentados com silagem de milho e ração concentrada à base de farelo de milho e soja, duas vezes por dia, fornecidas em baias individuais. As coletas de sangue foram realizadas a cada três dias, para determinação da concentração dos metabólicos sangüíneos. Para análise estatística, foram compilados dados a intervalo de três aplicações, o que constituiu um período (período 1, 2 e 3). As concentrações de ácidos graxos não-esterificados (NEFA) foram analisadas semanalmente. As concentrações séricas de colesterol, proteína total e plasmáticas de glicose diferiram para os períodos e nos grupos de tratamentos $(\mathrm{P}<0,05)$. As concentrações de NEFA foram influenciadas pelas semanas de coleta $(\mathrm{P}<0,05)$, mas não pelo tratamento com ou sem $\mathrm{r}-\mathrm{bST}(\mathrm{P}>0,05)$.
\end{abstract}

Palavras-chave: touro, hormônio do crescimento, r-bST, metabólitos séricos

\begin{abstract}
This study was carried out to evaluate the effect of recombinant bovine somatotropin ( $r$ - $b S T)$ administration on profiles of blood metabolites of two different ages Nellore bulls. Sixteen bulls were randomly allotted in a factorial arrangement $2 \times 2$ (ages: youngs and adults; and r-bST dose: 0 and $500 \mathrm{mg}$ ) with four animals per treatment. The mean ages of the young and adult animals were 13.37 and 20.62 months, respectively. Four animals per treatment received saline solution or $r$-bST 500mg, every 14 days, totaling nine applications per animal during 120 days. The Bulls were fed corn silage and concentrated diet based on corn crumb and soybean meal, twice a day, in individual stalls. Blood was collected every three days for metabolic evaluation. The statistical analyses of the data were performed in three applications, considering three periods (1, 2 and 3). Non-esterified fatty acid (NEFA) concentrations were weekly analyzed. Serum cholesterol, total protein and glucose levels were affected either by period or the treatment $(P<0.05)$. The NEFA was affected by weeks of collection $(P<0.05)$ but not by r-bST treatment $(P>0.05)$.
\end{abstract}

Key words: bulls, growth hormone, $r$-bST, serum metabolites

Recebido em 8 de novembro de 2005

Aceito em 2 de fevereiro de 2007

E-mail:1nlsamorimufv@yahoo.com.br 


\section{INTRODUÇÃO}

O hormônio do crescimento (GH) é um hormônio anabólico, secretado pelas células acidófilas do lobo anterior da hipófise, que diminui a deposição de gordura em virtude do aumento da deposição de proteína. Sua secreção é pulsátil e pode ser influenciada por vários sistemas de retroalimentação de complexidade peculiar, dentre os quais citam-se a glicose, insulina, ácidos graxos livres, somatostatina, etc.

As concentrações do $\mathrm{GH}$ nos bovinos variam em relação às diferentes faixas etárias, o que, presumivelmente, altera as secreções dos metabólitos sangüíneos. Burton et al. (1994) relataram que a concentração de $\mathrm{GH}$ nos bovinos varia de 10 a $15 \mathrm{ng} / \mathrm{ml}$, nos primeiros meses de vida, decaindo para 2 a $8 \mathrm{ng} / \mathrm{ml}$ durante a prépuberdade, atingindo picos de 15 a $18 \mathrm{ng} / \mathrm{ml}$ próximo à puberdade e estabilizando-se na faixa de 5 a $10 \mathrm{ng} / \mathrm{ml}$ no animal adulto.

O GH é responsável pelo aumento dos níveis hepáticos do fator de crescimento semelhante à insulina 1 (IGF-1), uma somatomedina que apresenta maior número de mRNA no fígado (Furlan,1998). Por meio do IGF-1, diretamente ou indiretamente, os processos anabólicos, como a divisão celular, o crescimento do esqueleto e a síntese de proteínas, são estimulados. Além disso, o GH promove efeitos metabólicos importantes, como elevação da taxa de oxidação de gorduras, inibição do transporte de glicose para os tecidos periféricos, e diminui a sensibilidade à insulina em animais hipofisectomizados (Frieden, 1995).

Os perfis metabólicos, originalmente delineados para rebanhos bovinos leiteiros (Payne et al., 1970), citados por González et al. (2000), foram posteriormente adaptados e utilizados com sucesso nos rebanhos de corte, e refletem as interações provocadas pelo excesso ou pela deficiência de um nutriente na alimentação, mas também avaliam a interação entre nutrientes (Contreras et al., 2000) e também os efeitos do tratamento de um hormônio anabólico (Amorim, 2004).

O tratamento com r-bST eleva a concentração sangüínea de $\mathrm{GH}$, dose dependente, a qual é acompanhada de elevação dos níveis de IGF-1. Logo após a administração de r-bST, verifica-se aumento de GH na corrente sangüínea que perdura por 4 a 8 horas, retornando a concentrações circulantes normais após esse período (Early et al., 1990). Observa-se que, em novilhos tratados com r-bST, as concentrações séricas de uréia, creatinina, bilirrubina e transaminase glutâmico-pirúvico (TGP) apresentam-se em menores níveis em relação aos de um grupo-controle. O decréscimo dos níveis séricos de uréia está correlacionado ao aumento na retenção de nitrogênio (aumento no ganho de peso), o mesmo observado quanto às concentrações de colesterol, que coincidem com o decréscimo na taxa de deposição de gordura na carcaça (Early et al., 1990). As concentrações de glicose e insulina são aumentadas em resposta ao tratamento com r-bST, criando um efeito de resistência à insulina (Breier e Sauerwein, 1995). Existe ainda correlação entre a concentração de colesterol e a taxa de deposição de gordura na carcaça em animais tratados com r-bST (Early et al., 1990). Schwarz et al. (1993) verificaram em novilhas de corte, em terminação, correlação positiva entre as concentrações de insulina e ácidos graxos livres, ao passo que as concentrações de glucagon e glicose praticamente não sofreram alteração em animais tratados ou não com r-bST. Nos ruminantes, a somatotrofina tem grande importância na estimulação da mobilização dos ácidos graxos na hipoglicemia, e esta, quando de longa duração, aumenta a formação de corpos cetônicos, devido à maior degradação de ácidos graxos, afetando a capacidade produtiva do animal (Prado et al., 2003).

Sabe-se do amplo aspecto comercial de uso da somatotrofina em vacas leiteiras, com grande potencial de alterar a produção da indústria leiteira (Lean et al., 1992), o que está relacionado ao aumento da produção de leite e aumento na persistência de lactação de animais tratados com r-bST (Bauman, 1992), porém pouco se sabe do seu uso em machos de corte em relação ao perfil metabólico (Amorim, 2004).

O conhecimento do perfil metabólico de touros tratados com somatotropina está relacionado ao entendimento das relações entre as concentrações dos metabólitos e o ganho de peso dos animais, o que servirá como um rastreador do metabolismo do animal. 
O objetivo deste trabalho foi a avaliação das concentrações de metabólitos sangüíneos (colesterol total, glicose, ácidos graxos nãoesterificados (NEFA), proteínas totais e uréia) em touros jovens e adultos da raça Nelore, tratados com somatotrofina bovina recombinante (r-bST), aplicadas a cada 14 dias.

\section{MATERIAL E MÉTODOS}

O experimento foi desenvolvido na Fazenda Aguadinha, localizada no município de CurveloMG e geograficamente posicionada a uma latitude de $19^{\circ} 3$ ' $27.4^{\prime \prime}$ (s) e longitude de $44^{\circ}$ 29' 24.1'" (w), com altitude de 790m. O clima da região é caracterizado como $\mathrm{Cwa}$, subtropical, com inverno seco e temperatura média do mês mais quente superior a $22^{\circ} \mathrm{C}$, segundo classificação de KÖPEN.

O período experimental foi de 120 dias, entre abril e agosto de 2004. Foram utilizados 16 machos da raça Nelore, distribuídos aleatoriamente em quatro tratamentos, de acordo com as idades e a dosagem de r-bST, em um delineamento fatorial $2 \times 2$ (idade e r-bST), com quatro animais por tratamento, sendo denominados: touros jovens-controle (JC) e jovens tratados (JT), touros adultos-controle
(AC) e touros adultos tratados (AT). Os animaiscontrole receberam solução salina, e os animais tratados receberam a aplicação subcutânea de $500 \mathrm{mg}$ de sometribove zinco $^{1}$ (r-bST), dose única, de liberação lenta; a cada 14 dias, totalizando nove aplicações de salina ou r-bST, conforme o grupo. Ao início do período experimental, os animais tinham idades médias de 13,37 e 20,62 meses e pesos corporais médios de 407 e $352 \mathrm{~kg}$, para animais jovens e adultos, respectivamente. Foram selecionados touros clinicamente saudáveis e em bom estado de escore de condição corporal, os quais receberam tratamento específico para endo e ectoparasitas antes do início do experimento.

Os animais foram confinados em baias individuais em galpão de alvenaria coberto com telha de barro, onde receberam água e sal mineral ad líbitum e alimentação fornecida duas vezes ao dia às 7 e às 15horas, sendo o concentrado constituído de farelo de milho, farelo de soja e mistura mineral, e, como volumoso, utilizou-se a silagem de milho. A composição bromatológica do volumoso e a do concentrado encontram-se na Tab. 1. A ração foi calculada de forma a proporcionar aos animais ganho médio diário de $1,1 \mathrm{~kg}$ (Nutrient..., 1996).

Tabela 1. Composição bromatológica da dieta em base da matéria seca

\begin{tabular}{lcccccc}
\hline Alimentos & $\mathrm{MS}(\%)$ & $\mathrm{MO}(\%)$ & $\mathrm{PB}(\%)$ & $\mathrm{EE}(\%)$ & $\mathrm{FDN}(\%)$ & $\mathrm{FDA}(\%)$ \\
\hline Volumoso & 28,01 & 99,13 & 5,83 & 1,34 & 53,78 & 30,50 \\
$\begin{array}{l}\text { Concentra } \\
\text { do }\end{array}$ & 90,38 & 98,98 & 28,72 & 2,11 & 8,66 & 4,56
\end{tabular}

$\mathrm{MS}=$ matéria seca; $\mathrm{MO}=$ matéria orgânica; $\mathrm{PB}=$ proteína bruta; $\mathrm{EE}=$ extrato etéreo; $\mathrm{FDN}=$ fibra em detergente neutro; FDA = fibra em detergente ácido.

As temperaturas de bulbo seco $(\mathrm{t})$, temperatura de bulbo úmido (tu) e temperatura de globo negro (tgn) foram registradas a cada quatro dias, para posterior cálculo do índice de temperatura de globo e umidade (ITGU), indicativo de conforto e estresse dos animais, conforme Buffington et al. (1981). ITGU $=\mathrm{T}_{\mathrm{gn}}+0,36 \mathrm{~T}_{\mathrm{po}}-$ 330,08 $\left(\mathrm{T}_{\mathrm{gn}}=\right.$ temperatura de globo negro, $\mathrm{K}$; e $\mathrm{T}_{\mathrm{po}}=$ temperatura de ponto de orvalho, $\mathrm{K}$ ).

As coletas de sangue foram realizadas a cada três dias, pela manhã, antes da alimentação dos animais, por punções da veia jugular, sendo o sangue

\footnotetext{
${ }^{1}$ Lactotropin ${ }^{\circledR}$ - Eli Lilly do Brasil Ltda. - São Paulo, Brasil.
}

recolhido em tubos de vidro vacuolizados de $10 \mathrm{ml}$, sem solução anticoagulante, para análise de colesterol total, ácidos graxos não-esterificados (NEFA), proteínas totais e uréia, exceto para glicose, para a qual se utilizaram tubos de vidro vacuolizados contendo solução anticoagulante à base de fluoreto de sódio. Após a coleta, os tubos foram acondicionados em caixa de isopor com gelo até a sua centrifugação, no período máximo de 45 minutos pós-coleta. As amostras foram centrifugadas a $1.000 \mathrm{~g}$ por 15 minutos, para obtenção do soro ou plasma, que foi aspirado, transferido para ependorfs e estocados a $-20^{\circ} \mathrm{C}$ até sua análise. Para as dosagens, realizadas em espectofotômetro de luz, utilizaram-se kits 
comerciais $^{2}$ por metodologia enzimática, de acordo com as especificações do fabricante, e as mesmas foram realizadas no laboratório de proteínas do BIOAGRO - UFV e no laboratório de reprodução animal do Departamento de Zootecnia - UFV.

Para as análises estatísticas, utilizou-se o programa SAEG (Sistema..., 2000). Os dados foram analisados por meio do teste variância, e as médias comparadas pelo teste Tukey com 5\% de erro. Para cada período, foi considerado o intervalo de três aplicações consecutivas de rbST, exceto para NEFA, que foi analisado em relação às semanas decorridas das aplicações.

\section{RESULTADOS E DISCUSSÃO}

As variáveis climáticas observadas ao longo do período experimental encontram-se sumarizadas na Fig. 1. O ITGU calculado apresentou valor médio para todo o período experimental (120 dias) de 69,05 $\pm 1,89$.

As temperaturas de globo negro, temperatura de bulbo seco e bulbo úmido, em valores absolutos, tenderam a exibir comportamento quadrático, apresentando picos durante a tarde e valores baixos ao início e final do dia, sendo as médias ao longo de todo o dia e para todo o período

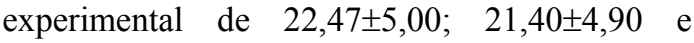
$17,11 \pm 2,4^{\circ} \mathrm{C}$, para tgn, $\mathrm{t}$ e tu, respectivamente. Segundo Baeta (1997), a zona de termoneutralidade para Bos taurus indicus está entre 10 e $27^{\circ} \mathrm{C}$. Assim, pode-se inferir que os animais deste estudo não estavam em situação de estresse por calor, conforme observado ao avaliar $\mathrm{t}$ e tu, que apresentaram valores limites à faixa de termoneutralidade dos animais.

A concentração sérica de colesterol total $\mathrm{em} \mathrm{mg} / \mathrm{dl}$ diferiu $(\mathrm{P}<0,05)$ entre os grupos de tratamento e entre períodos. Para o grupo de animais jovens, as concentrações de colesterol total não diferiram entre os tratamentos com e sem a aplicação de rbST $(\mathrm{P}>0,05)$, exceto para $\mathrm{P} 3$, no qual os animais

${ }^{2}$ Colesterol e úreia enzimáticos - Analisa Diagnóstica Ltda. Belo Horizonte, Brasil

Glicose enzimática - In vitro Diagnóstica Ltda. - Ribeirão Preto, Brasil

NEFA C (Ácidos Graxos Livres) - Wako Chemicals USA, Inc. - Richmond, EUA

Proteínas Totais - Doles Reag. Equip. Lab. Ltda. - Goiânia, Brasil
JT apresentaram maiores concentrações em relação ao JC. Para o grupo de animais adultos, as concentrações de colesterol total não diferiram entre o tratamento ou não com r-bST para o P1 e P3 $(\mathrm{P}>0,05)$, diferentemente do que aconteceu para o $\mathrm{P} 2$, em que se observaram maiores concentrações desse metabólito para $\mathrm{AC}$ em relação aos $\mathrm{AT}$ $(\mathrm{P}<0,05)$. Os animais adultos apresentaram maiores teores de colesterol total circulante que os animais jovens no P3 $(\mathrm{P}<0,05) \quad(\mathrm{Tab} .2)$, o que está relacionado à maior secreção desse metabólito em animais adultos.

Os níveis plasmáticos de colesterol total não foram influenciados pela aplicação de r-bST em dose única ou a cada 14 dias, em novilhas meio-sangue Nelore x Red Angus (Prado et al., 2003). Holzer et al. (1999), avaliando os efeitos da r-bST e progesterona + benzoato de estradiol, ao longo de 240 dias de experimento, em animais da raça Holandesa, não observaram diferença entre os tratamentos para as concentrações do colesterol total. Da mesma forma, Holzer et al. (2000), trabalhando com dois níveis de energia na dieta e dois níveis de r-bST, administrados em intervalos de duas semanas, também não observaram diferença entre os tratamentos em relação às concentrações desse metabólito. Early et al. (1990) encontraram declínio na taxa de colesterol no terço final do seu estudo, o que coincidiu com o decréscimo na taxa de deposição de gordura na carcaça.

O colesterol possui importante função metabólica por ser constituinte das membranas celulares, além de ser precursor dos hormônios sintetizados em tecidos esteroidogênicos (gônadas, adrenais, placenta), sobretudo no corpo lúteo (Borges et al., 2001) e testículos (Amorim, 2004)

Segundo Ferreira Neto et al. (1982), os valores séricos normais de colesterol para bovinos variam de 53 a $137 \mathrm{mg} / \mathrm{dl}$. Dessa forma, a concentração de colesterol dos animais deste estudo apresentaram-se dentro das concentrações normais. Variações na concentração de colesterol podem ocorrer, conforme a natureza da dieta. Neste sentido, Santos (1996) observou maiores concentrações de colesterol total em relação aos valores de referência, em touros da raça Nelore, de 24 meses de idade, tratados com diferentes níveis de concentrado e lipídeos na dieta (grão de soja), os quais apresentaram valores médios de $140 \mathrm{mg} / \mathrm{dl}$ de colesterol total sérico. 


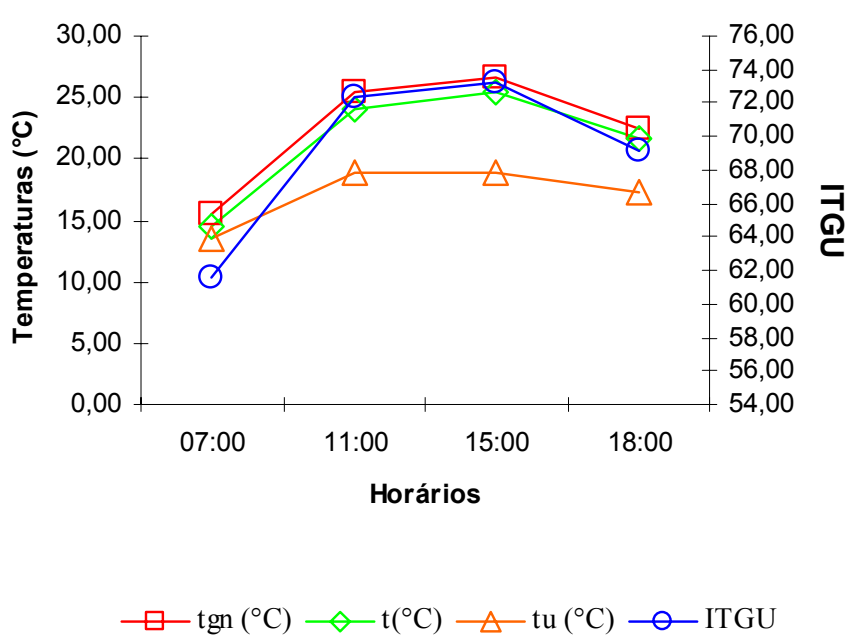

Figura 1. Médias da temperatura do ambiente do galpão, durante o período experimental, de abril a agosto de 2004, região de Curvelo-MG. (tgn= temperatura de globo negro, $t=$ temperatura de bulbo seco, $t u=$ temperatura de bulbo úmido, ITGU=índice de temperatura de globo e umidade).

Tabela 2. Médias das concentrações séricas de colesterol total $(\mathrm{mg} / \mathrm{dl})$ de touros da raça Nelore (Bos taurus indicus) tratados com r-bST, em função dos períodos experimentais

\begin{tabular}{ccccc}
\hline \multirow{2}{*}{ Períodos } & \multicolumn{4}{c}{ Tratamentos } \\
\cline { 2 - 5 } & $\mathrm{JT}$ & $\mathrm{JC}$ & $\mathrm{AT}$ & $\mathrm{AC}$ \\
\hline $\mathrm{Pl}$ & $86,66 \pm 19,07 \mathrm{ABb}$ & $77,82 \pm 21,75 \mathrm{Bb}$ & $94,79 \pm 23,28 \mathrm{Ab}$ & $98,59 \pm 35,34 \mathrm{Ab}$ \\
$\mathrm{P} 2$ & $95,55 \pm 23,15 \mathrm{Ba}$ & $86,27 \pm 14,24 \mathrm{Ba}$ & $96,32 \pm 23,51 \mathrm{Ba}$ & $117,04 \pm 29,79 \mathrm{Aa}$ \\
$\mathrm{P} 3$ & $91,92 \pm 26,43 \mathrm{Ba}$ & $78,95 \pm 14,63 \mathrm{Ca}$ & $115,88 \pm 18,95 \mathrm{Aa}$ & $123,92 \pm 31,16 \mathrm{Aa}$
\end{tabular}

JC: jovens não tratados; JT: jovens tratados com r-bST; AC: adultos não tratados; AT: adultos tratados com r-bST; P1: Período $1\left(1^{\circ}, 2^{\circ}\right.$ e $3^{\circ}$ aplicações de r-bST), P2 (4ㄷ, $5^{\circ}$ e $6^{\circ}$ aplicações de r-bST); P3: Período $3\left(7^{\circ}, 8^{\circ}\right.$ e $9^{\circ}$ aplicações de r-bST).

Médias seguidas por letras distintas, maiúscula na linha e minúsculas na coluna diferem entre si pelo teste Tukey $(\mathrm{P}<0,05)$

As concentrações plasmáticas de glicose $(\mathrm{mg} / \mathrm{dl})$, não foram influenciadas pela aplicação ou não de r-bST para os animais jovens $(\mathrm{P}<0,05)$, diferindo apenas em relação ao período de coleta $(\mathrm{P}>0,05)$. Para os animais do grupo adulto, os animais AT apresentaram maiores concentrações de glicose em relação aos $\mathrm{AC}(\mathrm{P}<0,05)$, e esta diferiu em relação aos períodos de coleta $(\mathrm{P}<0,05)$.

Sob efeito do r-bST, o transporte de glicose estaria bloqueado para os tecidos periféricos, condição conhecida como atividade diabetogênica, o que resultaria em maior quantidade líquida de glicose na circulação.
Schwarz et al. (1993) não verificaram diferenças nas concentrações de glicose em novilhas de corte, na fase de terminação, que receberam ou não r-bST.

As concentrações de ácidos graxos nãoesterificados (NEFA) em $\mathrm{mEq} / 1$ não foram influenciadas $(\mathrm{P}>0,05)$ pelos grupos de tratamento e nem pela interação tratamento $\mathrm{X}$ semanas de coletas (Fig. 2 e 3); porém, observou-se diferença nas concentrações séricas de NEFA $(\mathrm{P}<0,05)$ nas semanas de coletas para o JC e JT. 
Tabela 3. Médias das concentrações plasmáticas de glicose $(\mathrm{mg} / \mathrm{dl})$ de touros da raça Nelore (Bos taurus indicus) tratados com r-bST, em função dos períodos experimentais

\begin{tabular}{ccccc}
\hline \multirow{2}{*}{ Períodos } & \multicolumn{4}{c}{ Tratamentos } \\
\cline { 2 - 5 } & $\mathrm{JT}$ & $\mathrm{JC}$ & $\mathrm{AT}$ & $\mathrm{AC}$ \\
\hline P1 & $92,52 \pm 15,69 \mathrm{Bb}$ & $86,86 \pm 10,71 \mathrm{BCb}$ & $103,61 \pm 15,88 \mathrm{Ab}$ & $84,43 \pm 15,43 \mathrm{Cb}$ \\
$\mathrm{P} 2$ & $92,07 \pm 13,28 \mathrm{Ba}$ & $91,77 \pm 13,54 \mathrm{Ba}$ & $104,84 \pm 22,14 \mathrm{Aa}$ & $94,68 \pm 11,70 \mathrm{Ba}$ \\
P3 & $85,77 \pm 13,84 \mathrm{Bb}$ & $89,02 \pm 18,12 \mathrm{ABb}$ & $95,58 \pm 12,31 \mathrm{Ab}$ & $87,21 \pm 9,91 \mathrm{Bb}$ \\
\hline
\end{tabular}

JC: jovens não tratados; JT: jovens tratados com r-bST; AC: adultos não tratados; AT: adultos tratados com r-bST; P1: Período $1\left(1^{\circ}, 2^{\circ}\right.$ e $3^{\circ}$ aplicações de r-bST), P2 (4, $5^{\circ}$ e $6^{\circ}$ aplicações de r-bST); P3: Período $3\left(7^{\circ}, 8^{\circ}\right.$ e $9^{\circ}$ aplicações de r-bST).

Médias seguidas por letras distintas, maiúscula na linha e minúsculas na coluna diferem entre si pelo teste Tukey $(\mathrm{P}<0,05)$.

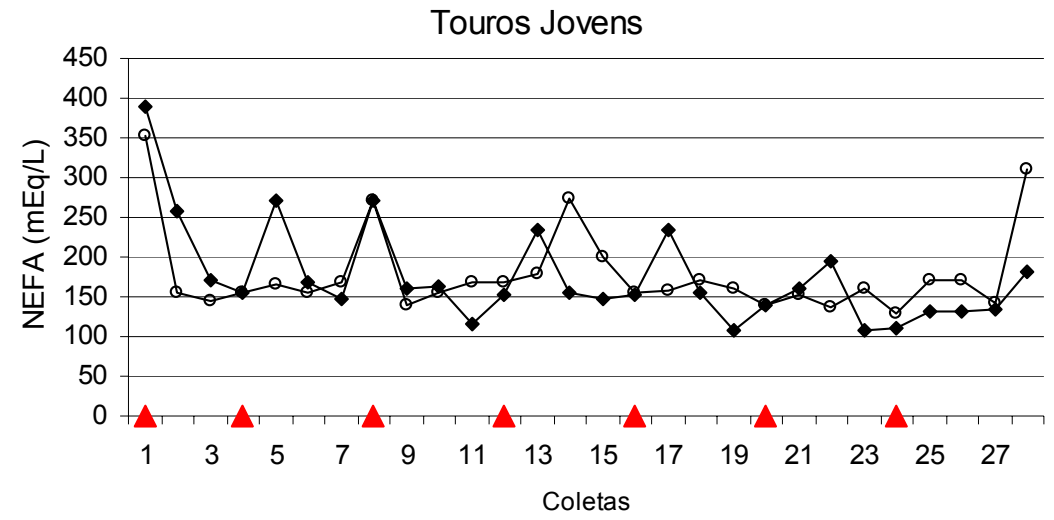

$\Delta$ Aplicação de salina ou r-bST — Jovens tratados $\multimap$ J Jovens controle

Figura 2. Médias das concentrações séricas de NEFA para touros jovens da raça Nelore (Bos taurus indicus) tratados com r-bST

As concentrações de NEFA estão relacionadas à mobilização de gorduras do tecido adiposo, estando sob a influência do IGF-1 e do GH. Resultados in vitro demonstram que o $\mathrm{GH}$ diminuiu drasticamente a lipogênese durante o período de tratamento com r-bST (Dante et al., 1995). No presente estudo, apesar da aplicação de r-bST a cada 14 dias, não se observou efeito dos tratamentos com r-bST sobre as concentrações de NEFA ( $\mathrm{P}>0,05)$ (Fig. 2 e 3 ).

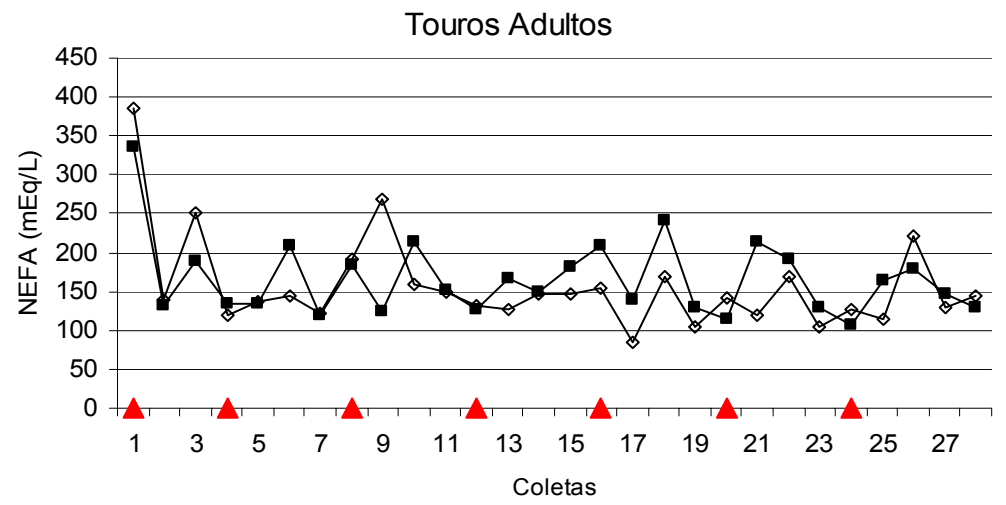

$\Delta$ Aplicação de salina ou r-bST $\rightarrow$ Adultos tratados $\multimap$ Adultos controle

Figura 3. Médias das concentrações séricas de NEFA $(\mathrm{mEq} / \mathrm{L})$ de touros adultos da raça Nelore (Bos taurus indicus) tratados com r-bST 
O aumento da lipólise nos adipócitos, estimulado pelo $\mathrm{GH}$, é regulado por vários mecanismos, incluindo aumento de resposta e sensibilidade aos agonistas $\beta$-adrenérgicos e redução de resposta e sensibilidade aos fatores como adenosina e prostaglandinas E. A importância relativa desses mecanismos depende da condição fisiológica do animal (Houseknecht et al., 1995). Possivelmente, no presente experimento, os níveis de NEFA não tenham sido influenciados pelos tratamentos, em virtude de a lipólise ser estimulada pela dose de r-bST, fato observado em novilhas tratadas com 320 e 640mg de r-bST. Nesse sentido, as altas concentrações de NEFA foram observadas no grupo que recebeu a maior dose de r-bST (Schwarz et al., 1993).

Segundo Hennies et al. (1998), citados por Breier (1999), tem-se observado que as concentrações circulantes de NEFA em animais adultos mostram maior efeito lipolítico em relação aos animais jovens. Em condição de aumento na demanda metabólica, como a lactação ou o ganho de peso, em que alto nível de energia é despendido, observa-se maior taxa plasmática nos níveis de NEFA. Não foi verificado aumento nas concentrações de NEFA em cordeiros jovens pré-púberes, que receberam salina ou 0,3mg/kg/dia de bGH (Ogawa et al., 1996).

O nível de NEFA no sangue está relacionado ao balanço energético do animal, em que altos valores de ácidos graxos livres são observados nos animais em balanço energético negativo. Em contrapartida, valores baixos são registrados quando o balanço energético é positivo (Peel e Bauman, 1986; Dante et al., 1995). Neste experimento, como os animais encontravam-se em balanço energético positivo, com ganho de peso vivo, puderam-se observar valores baixos de NEFA circulante.

As concentrações séricas de proteínas totais $(\mathrm{g} / \mathrm{dl})$ foram influenciadas $(\mathrm{P}<0,05)$ pelos grupos de tratamento, embora não tenha sido observado efeito da interação coleta $\mathrm{x}$ tratamento ou das semanas de coletas $(\mathrm{P}>0,05)$ (Tab. 4). O maior valor para a concentração de proteína total foi verificado em animais adultos do grupo-controle, encontrando-se os valores dentro da normalidade para bovinos, que é entre 66 e $90 \mathrm{~g} / 1$ (González et al., 2000). Tem-se verificado que a secreção de proteína total pode ser influenciada pela ingestão de alimentos e exigências do animal (Hewett, 1974).

Tabela 4. Médias das concentrações séricas de proteínas totais $(\mathrm{g} / \mathrm{dl})$ de touros da raça Nelore (Bos taurus indicus) tratados com r-bST, em função dos períodos experimentais

\begin{tabular}{ccccc}
\hline \multirow{2}{*}{ Períodos } & \multicolumn{4}{c}{ Tratamentos } \\
\cline { 2 - 5 } & $\mathrm{JT}$ & $\mathrm{JC}$ & $\mathrm{AT}$ & $\mathrm{AC}$ \\
\hline P1 & $6,24 \pm 0,95 \mathrm{Ba}$ & $6,43 \pm 0,56 \mathrm{Ba}$ & $6,45 \pm 0,82 \mathrm{Ba}$ & $6,91 \pm 0,48 \mathrm{Aa}$ \\
P2 & $6,51 \pm 0,68 \mathrm{Ba}$ & $6,50 \pm 0,92 \mathrm{Ba}$ & $6,74 \pm 1,15 \mathrm{Ba}$ & $7,16 \pm 0,58 \mathrm{Aa}$ \\
P3 & $6,47 \pm 0,89 \mathrm{Ba}$ & $6,37 \pm 1,18 \mathrm{Ba}$ & $6,71 \pm 0,74 \mathrm{Ba}$ & $7,23 \pm 0,57 \mathrm{Aa}$ \\
\hline
\end{tabular}

JC: jovens não tratados; JT: jovens tratados com r-bST; AC: adultos não tratados; AT: adultos tratados com r-bST; P1: Período $1\left(1^{\circ}, 2^{\circ}\right.$ e $3^{\circ}$ aplicações de r-bST), P2 (4, $5^{\circ}$ e $6^{\circ}$ aplicações de r-bST); P3: Período $3\left(7^{\circ}, 8^{\circ}\right.$ e $9^{\circ}$ aplicações de r-bST).

Médias seguidas por letras distintas, maiúscula na linha e minúsculas na coluna diferem entre si pelo teste Tukey $(\mathrm{P}<0,05)$.

As concentrações séricas de uréia em $(\mathrm{mg} / \mathrm{dl})$ diferiram $(\mathrm{P}<0,05)$ entre os animais dos tratamentos e entre os períodos de coleta, embora não tenha sido observada $(\mathrm{P}>0,05)$ interação coleta $\mathrm{x}$ tratamento $(\mathrm{P}>0,05)$ (Tab. 5).

Observaram-se maiores valores de uréia para os touros adultos do grupo-controle. Esperava-se, de fato, que as concentrações de uréia fossem menores para os animais jovens, independente do tratamento, em virtude de não terem ainda estabilizado seu crescimento e a retenção de nitrogênio, para ganho de peso e crescimento ósseo, refletida na menor concentração de uréia. $\mathrm{O}$ desvio do metabolismo provocado pelo r-bST para aumentar a deposição de proteína cria um desvio da uréia para a sua incorporação durante o balanço protéico positivo. 
Tabela 5. Médias das concentrações séricas de uréia ( $\mathrm{mg} / \mathrm{dl}$ ) de touros da raça Nelore (Bos taurus indicus) tratados com r-bST, em função dos períodos experimentais

\begin{tabular}{ccccc}
\hline \multirow{2}{*}{ Períodos } & \multicolumn{4}{c}{ Tratamentos } \\
\cline { 2 - 5 } & JT & JC & AT & AC \\
\hline P1 & $21,91 \pm 4,89 \mathrm{Bc}$ & $21,59 \pm 5,16 \mathrm{Bc}$ & $22,77 \pm 5,38 \mathrm{Bc}$ & $28,18 \pm 5,59 \mathrm{Ac}$ \\
P2 & $23,79 \pm 4,06 \mathrm{Bb}$ & $24,20 \pm 4,03 \mathrm{Bb}$ & $25,43 \pm 5,86 \mathrm{Bb}$ & $33,37 \pm 6,64 \mathrm{Ab}$ \\
P3 & $29,35 \pm 7,05 \mathrm{Ba}$ & $31,80 \pm 6,34 \mathrm{Ba}$ & $31,92 \mathrm{~B} \pm 6,63 \mathrm{Ba}$ & $39,66 \pm 9,23 \mathrm{Aa}$ \\
\hline
\end{tabular}

JC: jovens não tratados; JT: jovens tratados com r-bST; AC: adultos não tratados; AT: adultos tratados com r-bST; P1: Período $1\left(1^{\circ}, 2^{\circ}\right.$ e $3^{\circ}$ aplicações de r-bST), P2 ( $4^{\circ}, 5^{\circ}$ e $6^{\circ}$ aplicações de r-bST); P3: Período 3 ( $7^{\circ}, 8^{\circ}$ e $9^{\circ}$ aplicações de r-bST).

Médias seguidas por letras distintas, maiúscula na linha e minúsculas na coluna diferem entre si pelo teste Tukey $(\mathrm{P}<0,05)$.

A uréia representa a via metabólica protéica, uma vez que também depende de forma direta, do aporte de proteínas degradáveis na ração. Entretanto, o aporte energético da ração também tem efeito sobre as concentrações de uréia sangüínea, pois, se o consumo de energia for baixo, altera-se o metabolismo dos microrganismos ruminais. As concentrações de uréia no sangue também estão relacionadas ao estado protéico do animal (González et al., 2000). Segundo Contreras et al. (2000), valores limites para a condição protéica de bovinos de corte encontram-se abaixo de $15 \mathrm{mg} / \mathrm{dl}$ de uréia. De acordo com esta referência, os touros deste experimento apresentaram valores de uréia superiores aos relatados anteriormente, estando, no entanto, em balanço protéico positivo. Touros da raça Belgian Blue, submetidos à restrição alimentar, tiveram altas concentrações de $\mathrm{GH}$ circulante, e as concentrações de uréia observadas para animais jovens foram maiores em relação ao período de realimentação, no qual os níveis de GH foram menores (Hornick et al., 1998). Valores de referência para uréia sérica em bovinos adultos estão entre 20 e $40 \mathrm{mg} / \mathrm{dl}$, segundo Swesson e Reece (1993).

\section{CONCLUSÃo}

Nas condições experimentais estudadas, a administração de r-bST a touros jovens e adultos da raça Nelore altera os níveis de colesterol total sérico, glicose plasmática, NEFA sérico, proteínas totais sérica e uréia sérica. Os resultados deste estudo indicam que a r-bST aplicada em machos de corte indianos promove alterações metabólicas significativas que dependem da idade dos animais. Atenção especial deve ser dada quando do uso da r-bST como promotor do crescimento, pois este propicia desbalanço nos metabólitos sangüíneos, os quais estão relacionados ao ganho de peso.

\section{REFERÊNCIAS BIBLIOGRÁFICAS}

AMORIM, L.S. Características seminais, biometria testicular, concentrações metabólicas e hormonal e desempenho produtivo de touros da raça Nelore tratados com Somatotrofina bovina recombinante ( $r$ $b S T)$. 2004. 70f. Dissertação (Mestrado) Universidade Federal de Viçosa, Viçosa.

BAETA, F.C. Ambiência em edificações rurais conforto animal. Viçosa: UFV, 246p, 1997.

BAUMAN, D.E. Bovine Somatotropin: review of an emerging animal technology. J. Anim. Sci., v.75, p.3432-3451, 1992.

BORGES, A.M.; TORRES, C.A.A.; RUAS, J.R.M. et al. Concentração plasmática de colesterol total e lipoproteína de alta densidade em novilhas mestiças doadoras de embriões tratadas com somatotropina bovina recombinante. Arq. Bras. Med. Vet. Zootec., v.53, p.605-610, 2001.

BREIER, B.H. Regulation of protein and energy metabolism by the somatotropic axis. Domest. Anim. Endocrinol., v.17, p.209-218, 1999.

BREIER, B.H.; SAUERWEIN, H. Regulation of growth in ruminants by the somatotropic axis. In: INTERNATIONAL SYMPOSIUM ON RUMINANT PHYSIOLOGY, 8., 1995. Willinger, Ger. Proceedings..., Willinger, Ger. 1995. p.451-474

BUFFINGTON, D.E.; COLAZZO-AROCHO, A.; CANTON, G.H. et al. Black globe-humidity index (BGHI) as comfort equation for dairy cows. Trans. $A S A E$, v.24, p.711-714, 1981.

BURTON, J.L.; McBRIDE, B.W.O.; BLOCK, E. et al. A review of bovine growth hormone. Can. J. Anim. Sci., v.74, p.167-201, 1994.

CONTRERAS, P. Indicadores do metabolismo protéico utilizado nos perfis metabólicos de rebanhos. 
In: GONZÁLEZ, F.H.D.; BARCELLOS, J.O.; OSPINA, H. et al. (Eds). Perfil Metabólico em ruminantes: seu uso em nutrição e doenças nutricionais. Porto Alegre: UFRG, 2000. 108p.

DANTE, P.D.L.; KAREN, L.H.O.; DIANE, M.H. et al. Effect of somatotropin treatment on lipogenesis, lipolysis, and related cellular mechanism in adipose tissue of lactating cows. J. Dairy Sci., v.78, p.17031712, 1995

EARLY, R.J.; McBRIDE, B.W.; BALL, R.O. Growth and metabolism in somatotropin-treated steers: I Growth, serum chemistry and carcass weights. $J$. Anim. Sci., v.68, p.4134-4143, 1990.

FERREIRA NETO, J.M.; VIANA, E.S.; MAGALHÃES, L.M. Bioquímica do sangue. In FERREIRA NETO, J.M. (Ed). Patologia clínica veterinária. 2.ed. Belo Horizonte: Gráfica Rabelo, 1982. p.131-163.

FRIEDEN, E. Endocrinologia bioquímica dos vertebrados. São Paulo: Edgard Blucher Ltda., 1995. 130p.

FURLAN, L.R. Efeito do hormônio de crescimento bovino recombinante (rbst) sobre o desempenho $e$ expressão gênica do IGF-I, do hormônio de crescimento e seu receptor em bovinos de corte 1998. 86f. Tese (Doutorado) - Faculdade de Ciências Agrárias e Veterinárias, Universidade Estadual de São Paulo, Jaboticabal.

GONZÁLEZ, F.H.D.; BARCELLOS, J.O.; OSPINA, H. et al. (Eds). Perfil Metabólico em ruminantes: seu uso em nutrição e doenças nutricionais. Porto Alegre: UFRG, 2000. 108p.

HENNIES, M.; BREIER, B.H.O.; GALLAHER, B.W et al. Growth hormone induces electrolyte and metabolite imbalance in endotoxin challanged sheep. In: ANNUAL ENDOCRINE SOCIETY MEETING, 80., 1998, New Orleans. Proceedings..., New Orleans, 1998. p.1-8 (abstract).

HEWETT, C. On the causes and effects of variation in the blood profile of Suvidish dairy cattle. Acta Vet. Scan., v.50, p.7-144, 1974.

HOLZER, Z.; AHARONI, Y.; BROSCH, A. et al. The effect of long-term administration of recombinant bovine somatotropin (Posilac) and synovex on performance, plasma hormone and amino acid concentration, and muscle and subcutaneous fat fatty acid composition in Holstein-Friesian bull calves. $J$. Anim. Sci., v.77, p.1422-1430, 1999.
HOLZER, Z.; AHARONI, Y.; BROSH, A. et al. The influence of recombinant bovine somatotropin on dietary energy level-related growth of FriesianFriesian bull calves. J. Anim. Sci., v.78, p.621-628, 2000.

HORNICK, J.L.; VAN EENAEME, C.; DIEZ, M. et al. Different periods of feed restriction before compensatory growth in Belgian Blue bulls: II. Plasma metabolites and hormones. J. Anim. Sci., v.76, p.260$271,1998$.

HOUSEKNECHT, K.L.; BAUMAN, D.E.; CAREY, G.B. et al. Effect of bovine somatotropin and food deprivation on $\beta$-adrenergic and A1 adenosine receptor binding in adipose tissue of lactating cows. Domest .Anim. Endocrinol. , v.12, p.325-336, 1995.

LEAN, I.J.; TROUTT, F.H.; BALDWIN, R.L. Bovine somatotropin. Vet. Clin. N. Am.: Food Anim. Pract., v.8, p.175-179, 1992.

NUTRIENT requirements of beef cattle. 7.ed. Washington, D.C.: NCR, 1996. 242p.

OGAWA, E.; BREIER, B.H.; BAUER, M.K. et al Pretreatment with bovine growth hormone is as effective as treatment during metabolic stress to reduce catabolism in fasted lambs. Endocrinology, v.137, p.1242-1248, 1996.

PEEL, C.J.; BAUMAN, D.E. Somatotropin and lactation. J. Dairy. Sci., v.70, p.474-486, 1986.

PRADO, I.N.; NASCIMENTO, W.G.; NEGRÃO, J.A. et al. Somatotrofina bovina recombinante (r-BST) nos aspectos hematológicos e metabólicos do sangue de novilhas $\left({ }^{1 / 2}\right.$ Nelore $x{ }^{1 / 2}$ Red Angus) em confinamento. Rev. Bras. Zootec. v.32, p.465-472, 2003.

SANTOS, M.D. Perfil de testosterona e metabólitos lipídicos, circunferência escrotal e aspectos do sêmen de touros Zebu alimentados com dois níveis de concentrado e lipídeo. 1996. 68f. Dissertação (Mestrado) - Universidade Federal de Viçosa, Viçosa.

SCHWARZ, F.J.; SCHAMS, D.; ROPKE, R., et al. Effects of somatotropin treatment on growth performance, carcass traits, and endocrine system in finishing beef heifers. J. Anim. Sci., v.71, p.27212731, 1993.

SISTEMA para análises estatísticas e genéticas SAEG. Viçosa: UFV, 2000.

SWESSON, J.M.; REECE, W.O. (Eds). Dukes' Physiology of domestic animal. Cornell: Cornell University, 1993. 856p. 